\title{
RESENHA
}

\section{O MUNDO INTEIRO COMO LUGAR ESTRANHO}

Lucilene Cury ${ }^{1}$

Universidade de São Paulo, São Paulo, Brasil.

Este livro, O Mundo Inteiro como Lugar Estranho, recentemente publicado pela EDUSP, traz à luz uma obra pouco usual do antropólogo argentino radicado no México, Néstor García Canclini, bastante conhecido do público latino-americano por seus escritos relacionados à cultura, com destaque para o famoso livro - Culturas Híbridas e outros tantos, relacionados aos processos migratórios no âmbito da globalização.

Composto por 15 breves capítulos, o livro, de 171 páginas, aborda a questão da ciência nos dias atuais, de incerteza sob os avanços tecnológicos impactantes na comunicação e na vida cotidiana. Traz reflexões sobre as migrações, dentre outros temas, e examina fenômenos relacionados às crises urbanas e à geopolítica das artes e dos meios de comunicação, exponenciados pelo mundo digital, além de tratar da democracia, da política e da ciência em geral.

O Capítulo 1. "Lugar para a Dúvida" - Inicia o texto, articulado em forma de diálogo, apresentando a dúvida reinante nas ciências sociais e o lugar mais importante das perguntas que das respostas, quando propõe uma conversa sobre as perguntas, em vez das magistrais conferências cheias de certezas e repletas de imponências. Perguntas essas de grande importância no momento atual, como a seguinte: o que diferencia o real do virtual?

Assim, já nos primeiros capítulos: 2. Maneiras de Citar e 3. Quanto ou como se Lê, com bem-humorada escrita, o autor apresenta a realidade "oculta" de muitos jovens doutorandos e a dificuldade de definição do essencial para a tese no âmbito dos cruzamentos interdisciplinares da ciência, aliada à gama de compromissos que lhes são atribuídos.

Seguindo na trilha do mundo virtual, em tempos de cultura digital, instiga a fazer uma relação apropriada entre a leitura de livros (em papel) e a prática de leitura em telas, via twitter, blogs, redes sociais e livros digitais, dentre outros suportes tecnológicos. Questiona os

\footnotetext{
${ }^{1}$ Professora Associada na Escola de Comunicações e Artes da Universidade de São Paulo. E-mail: lucilene@usp.br. Recebido em: 26. jul. 2017; Aceito em: 3. Ago. 2017.
} 
resultados de pesquisa sobre o tema e, ao comentar dados de um Relatório Pisa do Programa Internacional de Avaliação de Estudantes cita [...] "A 'brecha digital' não depende apenas do acesso ou não aos livros ou à internet mas também de ampliar as capacidades das pessoas para integrarem, avaliarem e comunicarem informação". (GARCÍA CANCLINI, 2016, p.33)

No Capítulo 4. O que não podemos Responder, prossegue em seu texto repleto de fatos narrados de diferentes países, principalmente latino-americanos, discorrendo sobre as ciências modernas e a transdisciplina, quando afirma:

[...] os pesquisadores que admitem a insuficiência da própria área se reúnem com os de outros departamentos e reformulam suas perguntas. Desde Jean Piaget até Bruno Latour ou Richard Sennett, os cruzamentos transdisciplinares são feitos por gente com formação filosófica não dogmática, que leva a sério os dados de pesquisas de várias disciplinas. (GARCÍA CANCLINI, 2016, p.43)

Nessa importante discussão sobre a interdisciplinaridade, destaca-se sua explicação sobre a necessidade de construir um espaço, entre as disciplinas, que seja capaz de envolvêlas, de levar em conta sua trama interna e não apenas de conectá-las externamente, o que ocorre com muita frequência nas ciências hoje.

O conceito de culturas híbridas, de sua autoria, aparece em entrevista articulada no livro, como forma alternativa às conferências magistrais, porque envolvem o diálogo, de maneira a mostrar que o aumento de interconexões estendeu à noção de hibridação, que chega até a ser empregada para definir os carros que combinam energia elétrica com combustão interna, os chamados carros híbridos.

No capítulo cinco, que dá nome ao livro - O Mundo inteiro como Lugar Estranho o autor cita: “já não há lugar para onde ir" (GARCÍA CANCLINI, 2016, p.57), ao escrever sobre a impossibilidade da estraneidade (a perda de um território próprio), de habitar um mundo de teclas e ícones. O território da internet ou, o que ele chama de comunidade mundial, em contraste com o universo controlado dos amigos escolhidos, é uma discussão fecunda, que passa pela questão da privacidade e até da espionagem, tema de estudos cada vez mais necessários e urgentes nas sociedades hiper-conectadas destes dias. Pergunta ele: "o que significa habitar um mundo interconectado digitalmente onde é cada vez mais difícil ser estrangeiro"? (GARCÍA CANCLINI, 2016, p.59). 
Ao mesmo tempo, trata da questão das migrações, enfatizando o caso latino-americano e os Estados Unidos. Faz comparações com os chamados corriqueiramente de "nativos digitais", que é uma das grandes polêmicas entre os pesquisadores do tema da cultura digital, principalmente relacionada à educação. Os movimentos de protesto por mudanças sociais, articulados pelas redes sociais, não nascem dessas redes, mas nas sociedades reais, esclarece ele, através de pertencimentos múltiplos, de jogos de inclusão/exclusão e de estraneidades dispersas e segue aí discorrendo sobre o problema do público e do privado.

Com capítulos intitulados de maneira pouco ortodoxa, tais como: 6. Pós-Xerox; 7. Supermercado de Papers; 8. Por que existe a Literatura e Não o Nada; 9. Democracia Canalha, analisa as consequências das avaliações acadêmicas para as participações em congressos, as publicações em anais e outras exigências universitárias, que acabam por levar a ciência ao seu nível mais expositivo, com o fim de conseguir alianças, troca de e-mails, de cartões de visita, o que o leva a fazer uma indagação absolutamente pertinente: o que interessa mais, a biografia ou a bibliografia?

Ao tratar de uma conferência que fez em La Plata, cidade argentina de onde se exilou, Canclini, ao discorrer sobre arte e em especial, sobre a literatura, volta a tratar do trabalho interdisciplinar como consequência epistemológica, quando afirma: [...] "Só uma perspectiva interdisciplinar, ou melhor, transdisciplinar consegue abarcar o complexo de gestos, redes $e$ usos sem os quais um romance ou um poema não chegariam daqueles que o fazem àqueles que os leem" (GARCÍA CANCLINI, 2016, p.96).

Nos capítulos 10. Escolher o Quadro Teórico e 11. O Método, o autor discorre sobre teorias; métodos e textos científicos, de modo a provocar reflexões profundas sobre a ciência e suas práticas específicas em diversos níveis, tais como o dos cientistas, dos doutorandos e dos pós - doutorandos. Neles, a cena comunicacional e sua transformação na atualidade, que integra todos os meios e formatos, de modo a combinarem textos, imagens e sons, não escapa das reflexões do autor. Assim, o fazer noticioso de hoje faz desaparecer a hierarquia entre a imprensa e a televisão, de modo que todos são obrigados a acompanhar as notícias de última hora na internet, ainda que voltem aos meios impressos para aprofundamento das mesmas. 
Ligada à cena comunicacional figura a necessidade de compreender o que acontece no consumo e no acesso à comunicação, principalmente nas novas gerações de usuários de tecnologia digital, no seu papel de público e, também, de criadores.

O Capítulo 12. Por que os Cientistas escrevem Ensaios, trata da questão abrangente sobre o ensaio e sua imbricação na ciência. Apresenta aí o seguinte diálogo:

Em que se diferencia o ensaio científico do filosófico ou literário?

- A escrita científica não pode se sustentar só com ideias ou hipóteses do autor. Ela se baseia em pesquisas [...]. Como sabemos desde Popper, o cientista não busca chegar à verdade, mas refutar o que acredita ter descoberto: enquanto não refuta dirá que seus enunciados mantêm seu temperamento, sua verossimilhança. As estratégias persuasivas do discurso humanístico obturam, muitas vezes, essa possível autorreflexão e refutação. (GARCÍA CANCLINI, 2016, p. 137-138)

Nos Capítulos 13. Deixam a Gente Simular Menos: Da Televisão a Snowden; 14. Intempérie e 15. Fontes e Versões, o autor, sempre com sua bem humorada escrita, incluindo aí uma fina ironia, que só faz aumentar o interesse pela leitura, dispensa coerentemente a bibliografia dos tratados científicos, como ocorre no livro e justifica essa ausência: “[...] Seria contraditório com o sentido deste livro dar uma bibliografia que distinguisse nitidamente os autores, textos e congressos citados dos que são ficcionais [...] aparecem alguns nomes de expositores em congressos, ainda que não tenham ocorrido como são relatados[...]" (GARCÍA CANCLINI, 2016, p.169).

As conferências convertidas em entrevistas, para dar um tom coloquial e a intenção de não interromper a fluidez da leitura com precisões acadêmicas, conforme afirma o autor, fazem do livro um modelo surpreendentemente bom de tratar questões tão sérias como as aqui já expostas, de maneira suave e de grande significado para todos que, na Academia, utilizam o senso crítico para compreender seu próprio trabalho, assim como o dos seus pares, no âmbito da realidade social em que se inserem.

De maneira muito especial, Canclini cita o nome do Professor espanhol, naturalizado colombiano, Jesús Martin-Barbero, de quem recebeu a solicitação de fazer uma versão do texto sobre interdisciplina, que compõe o Capítulo 4. Dentre outros agradecimentos a universidades em que esteve e que estão devidamente apresentadas no livro, enfatiza a Universidade de São Paulo e o papel dos estudantes que foram importantes para que ele pudesse escutar as perguntas sobre seus modos de buscar informações e suas dúvidas sobre as certezas clássicas das ciências sociais.

\section{REFERÊNCIA}


GARCÍA CANCLINI, Néstor. O Mundo Inteiro como Lugar Estranho. Tradução de Larissa Fostinone Locoselli. São Paulo: EDUSP, 2016.

Recebido em 26/06/2017.

Aceito em 03/08/2017.

Publicado em 21/08/2017.

DOI: 10.11606/issn.1676-6288.prolam.2016.133980 